\title{
Aperistaltic oesophageal disorders unmasked by severe post-fundoplication dysphagia
}

\author{
C.J. O'Brien, J.S.A. Collins, B.J. Collins and J. McGuigan'
}

Department of Medicine, Royal Victoria Hospital, Belfast BT12 6BA and ${ }^{1}$ Thoracic Surgery Unit, Royal Victoria Hospital, Belfast BT12 6BA, UK

Summary: Two patients were referred because of persistent dysphagia which developed for the first time after Nissen fundoplication. Investigations, including oesophageal manometry, demonstrated the presence of achalasia in one case, confirmed histologically, and aperistaltic oesophagus associated with an underlying connective tissue disorder in the other case. Our observations highlight the importance of assessing oesophageal motility before referring patients for anti-reflux surgery and illustrate the efiect of such surgery on patients in whom oesophageal dysmotility was not suspected.

\section{Introduction}

Anti-reflux surgery is reserved for patients with gastro-oesophageal reflux who have symptoms resistant to medical therapy or who develop complications. ${ }^{1}$ A major abnormality underlying reflux is incompetence of the lower oesophageal sphincter. ${ }^{2}$ The transmission of positive intra-abdominal pressure around the distal oesophagus by means of a surgical wrap is highly effective in reducing symptoms and preventing complications. ${ }^{3}$ Occasionally, too tight a fundoplication results in gastric fullness and difficulty in eructation after meals, although, in the absence of an oesophageal stricture, prolonged dysphagia is a very infrequent operative complication. ${ }^{3,4}$ Presumably, normal oesophageal body peristalsis, even if of reduced amplitude, can overcome a modest increase in distal oesophageal resistance, whereas in patients with conditions associated with oesophageal body aperistalsis, fundoplication can precipitate severe dysphagia. ${ }^{5}$ In the cases described in this paper, the presence of an adynamic oesophagus was only revealed by the onset of persistent post-fundoplication dysphagia. Our observations support a role for routine evaluation of oesophageal motility in all patients being considered for antireflux surgery since an aperistaltic oesophagus is not always clinically apparent.

Correspondence: C.J. O'Brien, M.D., M.R.C.P., Gastroenterology Unit, Royal Hallamshire Hospital, Sheffield S10 2JF, UK

Accepted: 25 May 1990

\section{Case reports}

\section{Case 1}

A 56 year old female presented with a 4-year history of heartburn, nausea and intermittent vomiting but no dysphagia. Barium meal examination revealed a reducible hiatus hernia although no reflux was seen. As symptoms were unrelieved by standard medical treatment, which included $\mathrm{H}_{2}$ antagonist therapy, Nissen fundoplication was performed. Dysphagia appeared immediately on re-feeding. An oesophagoscopy revealed no stricture and bouginage failed to ameliorate the dysphagia which persisted for solids and liquids and resulted in a weight loss of $38 \mathrm{~kg}$ in 9 months. The patient was referred to the Royal Victoria Hospital and oesophageal manometry, carried out at this stage, revealed absent lower (smooth muscle) oesophageal peristalsis. The manometry catheter could not be passed across the lower oesophageal sphincter. Fibreoptic endoscopy revealed no stricture and no oesophagitis. Achalasia was suspected from these findings and further surgery performed with a view to carrying out a Heller's myotomy and taking down the fundoplication. Severe perioesophagitis seen at thoracotomy precluded this approach and a resection of distal half of oesophagus and gastric cardia was performed. Histology of the resected specimen revealed muscular and neural hypertrophy and the virtual absence of ganglion cells in keeping with achalasia. The patient's dysphagia was considerably improved after the operation. 
Case 2

A 55 year old female was referred with heartburn for 5 years and recent coffee ground vomiting. There was no dysphagia. Physical examination was normal and a barium study showed a hiatus hernia and gross gastro-oesophageal reflux. After failed medical management a Nissen fundoplication was performed. Severe dysphagia ensued immediately and only a liquid diet has been possible for the last year. Manometry, carried out 6 months after the surgery, revealed aperistalsis in the oesophageal body and reduced lower oesophageal sphincter pressure. $\mathrm{pH}$ monitoring showed persisting acid reflux with impaired acid clearance. Subsequent enquiry elicited a one year history of cold-induced pallor and pain affecting the finger tips. Further investigations demonstrated normal renal and liver function tests, a weakly positive cold pressor test and positive antinuclear $(1: 40)$ and anti-double stranded DNA antibody $(5.7 \mathrm{mg} / \mathrm{l})$. Ribonucleoprotein antibody was not detected. These features were in keeping with the presence of an underlying connective tissue disorder.

\section{Discussion}

We believe that the exclusion of an underlying oesophageal motility disorder is advisable in all patients being considered for fundoplication. Strengthening the lower oesophageal sphincter zone of an aperistaltic oesophagus, even when non-obstructive symptoms and the presence of a hiatus hernia suggest reflux alone, can, as illustrated, precipitate almost total dysphagia.

An aperistaltic oesophagus may result from localized conditions - classically achalasia in which case the lower oesophageal sphincter also fails to relax on deglutition ${ }^{6}$ - or multisystem collagen vascular disorders such as systemic sclerosis, mixed connective tissue disease, systemic lupus erythematosus (SLE) ${ }^{7-9}$ or dermatomyositis, ${ }^{10}$ in which instances lower oesophageal sphincter pressure is generally reduced. In achalasia, the combination of absent oesophageal peristalsis and a poor relaxing often hypertensive lower oesophageal sphincter results in impaired swallowing being an early and prominent complaint. " Dysphagia may, however, be intermittent, trivial or, in rare cases, absent. ${ }^{12}$ In patients presenting with oesophageal symptoms, a hiatus hernia makes the diagnosis of achalasia extremely unlikely. Thus, whereas a hiatal hernia is fairly common in the general population, with a frequency of $40-50 \%$, a recent large series found a hiatal hernia in only 3 of $260(1.2 \%)$ patients with achalasia. ${ }^{13}$

In our first patient, dyspeptic symptoms in the absence of dysphagia and the finding of a hiatus hernia led to an erroneous although perhaps understandable diagnosis of simple gastro-oesophageal reflux. Achalasia was only considered following the appearance of persistent post-fundoplication dysphagia. Surgery required to alleviate this problem allowed us to confirm the presence of achalasia by histological examination. Another retrospective diagnosis based on oesophageal manometry and also immunological testing was made in our second case. The combination of an aperistaltic distal oesophagus and reduced lower oesophageal sphincter pressure is most commonly seen in systemic sclerosis or mixed connective tissue disease. Abnormal oesophageal motility is found in up to $80 \%$ of such patients and correlates with the presence of Raynaud's phenomenon. ${ }^{8,9,14}$ Only rarely do gastrointestinal symptoms precede all other features of disease. ${ }^{15}$ Significant oesophageal involvement is much less frequent in patients with systemic lupus erythematosus ${ }^{9}$ although among collagen vascular disorders anti-double stranded DNA antibodies, as found in our patient, are specific for SLE. Overlap syndromes are, howeverO recognized in which scleroderma predominantl affecting the gastrointestinal tract coexists witk SLE. ${ }^{16}$ Whether our patient is an example of this or whether her condition will later evolve to classical systemic sclerosis or SLE is unknown.

Anti-reflux surgery in patients with sclerodermatype oesophageal involvement can be beneficial although complications are not infrequent. ${ }^{17}$ Preoperative manometry is routinely used in some centres to identify those patients who have oesophageal aperistalsis. Barium radiology with the patient supine or head down, oesophageal $\mathrm{pH}$ monitoring with assessment of acid clearance and radioisotope studies of oesophageal transit may also suggest the presence of oesophageal dysmotility, and help to select patients who require formal manometric evaluation. In such cases modifying the procedure to reduce the wrap length can minimize the risk of post-operative dysphagia. ${ }^{17}$ The problem remains that if motility is not assessed in all patients being considered for anti-reflux surgery rare cases of atypically presenting oesophageal motor disorders can be overlooked. If inappropriate surgery is then performed severe and intractable dysphagia can result. 


\section{References}

1. Skinner, D.B. Hiatal hernia and gastroesophagus. In: Sabiston, D.C. (ed.) Textbook of Surgery. W.B. Saunders, Philadelphia, 1981, pp. 821-834.

2. Dent, J., Holloway, R.H., Toouli, J. \& Dodds, W.J. Mechanisms of lower oesophageal sphincter incompetence in patients with symptomatic gastroesophageal reflux. Gut 1988, 29: $1020-1028$.

3. DeMeester, T.R., Johnson, L.F. \& Kent, A.H. Evaluation of current operations for the prevention of gastroesophageal reflux. Ann Surg 1974, 180: 511-516.

4. Garstin, W.I.H., Johnston, G.W., Kennedy, T.L. \& Spencer, E.F.A. Nissen fundoplication: the unhappy $15 \%$. $J R$ Coll Surgeons Edinb 1986, 31: 207-209.

5. Richter, J.E. \& Castell, D.O. Gastroesophageal reflux. Pathogenesis, diagnosis and therapy. Ann Intern Med 1982, 97: 93-103.

6. Vantrappen, G. \& Hellemans, J. Treatment of achalasia and related motor disorders. Gastroenterology 1980, 79: 144-154.

7. Turner, R., Lipshutz, W., Miller, W., Rittenberg, G., Schumacher, H.R. \& Cohen, S. Esophageal dysfunction in collagen disease. Am J Med Sci 1973, 265: 191-199.

8. Hurwitz, A.L., Duranceau, A. \& Postlethwait, R.W. Esophageal dysfunction and Raynaud's phenomenon in patients with scleroderma. Am J Dig Dis 1976, 21: 601-606.
9. Gutierrez, F., Valenzuela, J.E., Ehresmann, G.R., Quismorio, F.P. \& Kitridou, R.C. Esophageal dysfunction in patients with mixed connective tissue diseases and systemic lupus erythematosus. Dig Dis Sci 1982, 27: 592-597.

10. Kleckner, F.S. Dermatomyositis and its manifestations in the gastrointestinal tract. Am J Gastroenterol 1970, 53: 141-146.

11. Mayberry, J.F. \& Atkinson, M. Studies of incidence and prevalence of achalasia in the Nottingham area. $Q J \mathrm{Med}$ 1985, 56: 451-456.

12. Harley, H.R.S. Achalasia of the Cardia. Wright, Bristol, 1978.

13. Taub, W. \& Achaer, E. Hiatal hernia in patients with achalasia. Am J Gastroenterol 1987, 82: 1256-1258.

14. Cohen, S. Motor disorders of the esophagus. $N$ Engl J Med 1979, 301: 184-192.

15. Treacy, W.L., Bunting, W.L., Gambill, E.E. \& Code, C.F. Scleroderma presenting as obstruction of the small bowel. Mayo Clin Proc 1962, 37: 607-616.

16. Ferreiro, J.E., Busse, J.C. \& Saldana, M.J. Megacolon in a collagen vascular overlap syndrome. Am J Med 1986, 80: 307-311.

17. Henderson, R.D. \& Marryatt, G.V. Total fundoplication gastroplasty (Nissen gastroplasty): five year review. Ann Thorac Surg 1985, 39: 74-79. 